\title{
Analysis of Ultrafine TATB by Ultrasonic-Assisted Equilibrium Headspace Analysis
}

\author{
D. M. Chambers
}

September 12, 2000

U.S. Department of Energy

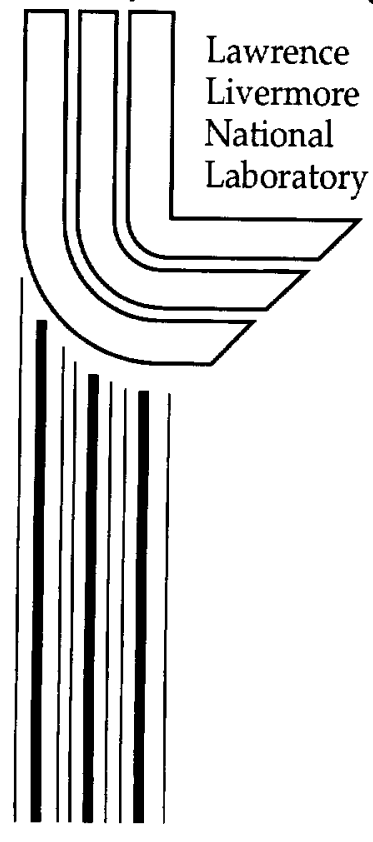

Approved for public release; further dissemination unlimited 


\section{DISCLAIMER}

This document was prepared as an account of work sponsored by an agency of the United States Government. Neither the United States Government nor the University of California nor any of their employees, makes any warranty, express or implied, or assumes any legal liability or responsibility for the accuracy, completeness, or usefulness of any information, apparatus, product, or process disclosed, or represents that its use would not infringe privately owned rights. Reference herein to any specific commercial product, process, or service by trade name, trademark, manufacturer, or otherwise, does not necessarily constitute or imply its endorsement, recommendation, or favoring by the United States Government or the University of California. The views and opinions of authors expressed herein do not necessarily state or reflect those of the United States Government or the University of California, and shall not be used for advertising or product endorsement purposes.

This work was performed under the auspices of the U.S. Department of Energy by the University of California, Lawrence Livermore National Laboratory under Contract No. W-7405-Eng-48.

This report has been reproduced directly from the best available copy.

Available electronically at http://www.doc.gov/bridge

Available for a processing fee to U.S. Department of Energy

And its contractors in paper from

U.S. Department of Energy

Office of Scientific and Technical Information

P.O. Box 62

Oak Ridge, TN 37831-0062

Telephone: (865) 576-8401

Facsimile: (865) 576-5728

E-mail: reports@adonis.osti.gov

Available for the sale to the public from

U.S. Department of Commerce

National Technical Information Service

5285 Port Royal Road

Springfield, VA 22161

Telephone: (800) 553-6847

Facsimile: (703) 605-6900

E-mail: orders@ntis.fedworld.gov

Online ordering: http://www.ntis.gov/ordering.htm

OR

Lawrence Livermore National Laboratory

Technical Information Department's Digital Library

http://www.llnl.gov/tid/Library.html 


\title{
Lawrence Livermore National Laboratory
}

\section{Analysis of Ultrafine TATB by Ultrasonic-Assisted Equilibrium Headspace Analysis Files RW002723-37}

Version Date: September 12, 2000

Prepared by:

David M. Chambers, Ph.D.

chambers10@llnl.gov

Weapons Materials Compatibility \& Aging Program Element

Lawrence Livermore National Laboratory, Livermore CA 94551

P.O. Box 808, L-178

Livermore, CA 94551

Phone (925) 422-5607

FAX: (925) 423-9014

\begin{abstract}
In this work we analyzed volatile and semivolatile products obtained from stockpile-aged ultrafine 1,3,5- triamine-2,4,6-trinitrobenzene (TATB) (Lots 1169-135MPS-001, 4271$135 \mathrm{M}-002,, 91190-135 \mathrm{M}-003$ and $98170-135 \mathrm{M}-001$ ) by ultrasonic-assisted outgas sample preparation. Using this approach, we targeted the analysis of volatile and semivolatile species that were trapped within and/or adsorbed by the ultrafine TATB. The species that were found primarily include TATB synthesis aids and process contaminants. For example, toluene, which is incorporated into the TATB crystalline structure during synthesis, was detected at low and sub $\mu \mathrm{g} / \mathrm{g}$ levels. Within the limited sample group that was analyzed, toluene concentration appeared to decrease with the age of the lot. We also identified relatively high levels of compounds that are likely process or post-process contaminants that include 3-ethoxy-2-methyl-1-propene and a number of long-chain aldehydes. The aldehyde signature was initially believed to originate from the toluene/water emulsifier, Atlox 5050, used in the amination step of the 1,3,5-trichloro2,4,6-trinitrobenzene precursor. However, upon analysis of the emulsifier, we were unable to identify any aldehyde byproducts, thus, indicating it was not the source. Because of its conjugated $p i$ structure and polar side groups, TATB likely possesses relatively strong adsorbent characteristics that may result in accumulation of these and other species as process contaminants.
\end{abstract}




\section{ANALYSIS OF ULTRAFINE TATB BY ULTRASONIC-ASSISTED EQUILIBRIUM HEADSPACE ANALYSIS}

David M. Chambers, Ph.D.

Weapons Materials Compatibility \& Aging Program Element

Lawrence Livermore National Laboratory, Livermore CA 94551

\section{BACKGROUND}

The purpose of this work was to screen different lots of ultrafine 1,3,5-triamine 2,4,6trinitrobenzene (TATB) for chemical differences, which may include synthesis and formulation byproducts, decomposition products, and contaminants. The approach used here permits analysis of trapped species as volatile and semivolatile chemicals within a solid. This procedure involves preconcentration of species from the TATB matrix into a surrounding headspace followed by a preconcentration and collection step using solid phase microextraction (SPME) collection. The sample is prepared by sealing it in a glass ampule with a few milliliters of water, ultrasonicating the solution, and then sampling the headspace using SPME collection. Water couples in the ultrasonic energy to fracture the TATB, which permits the release of nonpolar species into the gas phase. However, polar species will favor the aqueous phase and require a separate analysis procedure, which is not included here. ${ }^{1}$ Following SPME collection, the sample is transferred to a gas chromatography/mass spectrometer (GC/MS) for analysis.

In this work, we analyzed and interpreted outgas signatures from four different lots (1169-135MPS-001, 4271-135M-002, 91190-135M-003, and 98170-135M-001) of ultrafine TATB. Lot $98170-135 \mathrm{M}-001$ is a reprocessing of Lot $4271-135 \mathrm{M}-002$, which was washed to remove the water-soluble polysaccharides. The pedigree for these materials are found in a memo from Tom Stallings and Gordon Osborn of Mason \& Hanger Co., Pantex Plant in the Appendix section. Nominally, ultrafine TATB is synthesized via the emulsion-amination method in which an emulsifier is included during the amination of the 1,3,5-trichloro-2,4,6-trinitrobenzene (TCTNB) precursor. The ultrafine TATB formulation also includes $0.2 \%$ by weight guar gum, a galactomannan polysaccharide, to enhance flow properties. Historically, this polysaccharide was added to PETN to reduce its sublimation temperature, but it was also found to enhance flow characteristics, thus improving processing.

\section{EXPERIMENTAL}

For these analyses, we sonicated $10 \mathrm{mg}$ of ultrafine TATB with $1-\mathrm{ml}$ water in a sealed 2$\mathrm{ml}$ glass ampule for approximately $6 \mathrm{hrs}$. Following the sonication, the vial was sealed in standard $20-\mathrm{ml}$ headspace vial and broken open by shaking. This transfer to the larger headspace vial, which uses a septum crimp cap, permits sampling by SPME.

${ }^{1}$ Quinlin, W.T.; Schaffer, C.L. “Water-Aminated TATB Analytical Closure”, Mason \& Hanger Co., Pantex Plant, August 1985, MHSMP-85-30. 
For SPME collection we used a 100- $\mu$ m polydimethyl siloxane (PDMS) coated fiber that was exposed to the vial headspace for $30 \mathrm{~min}$. This method was selected because of its high collection and preconcentration efficiency for gas-phase compounds. This method targets collection and analysis of nonpolar volatile and semivolatile compounds that are otherwise difficult to prepare by liquid extraction because of their volatility, dilution and interference by solvent extraction.

Analyses were performed on a Hewlett-Packard 5890/5972 GC/MS analyzer with a 0.75$\mathrm{mm}$ I.D. injection port liner. The GC separation was performed with a 60 -m long $\times 0.25$ $\mathrm{mm}$ I.D. capillary coated with a $1.4-\mu \mathrm{m}$ thick (6\%-cyanopropyl-phenyl)methylpolysiloxane (J\&W Scientific, DB-624). This column, which permits the analysis of volatile compounds at relatively high GC oven temperatures, was primarily used to take advantage of the existing retention-time database that we maintain for this column phase.

\section{RESULTS}

We found 13 significant compounds. Total mass chromatograms comparing the chemical signatures are shown in Fig. 1. The list of these compounds and their single ion monitoring (SIM) responses for a significant ion are given in Table I. The significant ion is selected on the basis of its relative response and freedom from interferences.

Structures for these compounds can be found upon referencing their CAS number at http://www.chemfinder.camsoft.com/.

Among the different ultrafine TATB lots we saw many of the same compounds. As shown in Table I, each of the compounds identified was detectable in the different lots. The most striking similarity between all the lots was the long-chain aldehyde signature, which includes compounds $2,3,6,8$ and 9 . However, relative levels of trace compounds found in lot 4271-135M-002 were somewhat different than those of lots 1169-135-MSP001 and $91190-135 \mathrm{M}-003$. As expected the signature for lot $98170-135 \mathrm{M}-001$ is similar to the lot from which it was reprocessed (i.e., lot 4271-135M-002). 
Table I. Outgas signature list for ultrafine TATB.

\begin{tabular}{|c|c|c|c|c|c|c|c|c|c|}
\hline & & & \multicolumn{7}{|c|}{ Run Number RW0027* } \\
\hline & & & $* 23$ & $* 37$ & & $* 27$ & & & \\
\hline & Compound & CAS Number & $\begin{array}{c}\text { 1169-135-MSP-001 } \\
(1981)\end{array}$ & $\begin{array}{c}\text { 4271-135M-002 } \\
(1984)\end{array}$ & $\begin{array}{c}98170-135 M-001 \\
\text { (1984 reprocessed } \\
1999) \\
\end{array}$ & $\begin{array}{c}91190-135 M-003 \\
(1991)\end{array}$ & $\begin{array}{l}\text { R.T. } \\
\text { (min) }\end{array}$ & Sig. Ion & $\begin{array}{c}\text { MW } \\
\text { (amu) }\end{array}$ \\
\hline 1 & toluene & $108-88-3$ & $\begin{array}{r}254688 \\
(1.1 \mu \mathrm{g} / \mathrm{gm}) \\
\end{array}$ & $\begin{array}{r}906008 \\
(4.7 \mu \mathrm{g} / \mathrm{gm}) \\
\end{array}$ & $\begin{array}{r}561429 \\
(2.9 \mu \mathrm{g} / \mathrm{gm}) \\
\end{array}$ & $\begin{array}{r}1601847 \\
(8.3 \mu \mathrm{g} / \mathrm{gm}) \\
\end{array}$ & 15.578 & 91 & 92 \\
\hline 2 & hexanal & $66-25-1$ & 392518 & 445141 & 961680 & 215403 & 16.721 & 56 & 100 \\
\hline 3 & heptanal & $111-71-7$ & 107353 & 179201 & 240233 & 98207 & 19.331 & 70 & 114 \\
\hline 4 & 3-ethoxy-2-methyl-1-propene & $24309-28-2$ & 2108865 & $\mathrm{ND}$ & 10246 & 4589364 & 20.093 & 57 & 100 \\
\hline 5 & benzaldhyde & $100-52-7$ & 154311 & 12768 & 7915 & 109401 & 21.506 & 77 & 106 \\
\hline 6 & octanal & 124-13-0 & 123630 & 195922 & 288864 & 132355 & 21.712 & 84 & 128 \\
\hline 7 & octanol & $11-87-5$ & 21527 & 43306 & 34894 & 14913 & 23.198 & 70 & 130 \\
\hline 8 & nonanal & $124-19-6$ & 154140 & 359016 & 459233 & 172782 & 23.903 & 98 & 142 \\
\hline 9 & decanal & $112-31-2$ & 444002 & 1122662 & 1647012 & 486247 & 25.922 & 57 & 156 \\
\hline 10 & $\mathrm{DBQ}$ & $719-22-2$ & $\mathrm{ND}$ & 480624 & 436758 & 16597 & 31.295 & 177 & 220 \\
\hline 11 & Aromatic phenol & $25013-16-5$ & 13597 & 262974 & 270619 & 25740 & 31.371 & 165 & 180 \\
\hline 12 & Aromatic hydrocarbon & $00000-00-0$ & 2835 & 75326 & 146725 & ND & 32.914 & 221 & Unk \\
\hline 13 & Aromatic hydrocarbon & $00000-00-0$ & 144944 & 3336674 & 1856828 & 75128 & 36.171 & 221 & 236 \\
\hline
\end{tabular}

$\mathrm{R} . \mathrm{T}=$ retention time, $\mathrm{Sig}$. Ion = significant ion, $\mathrm{MW}=$ molecular weight 

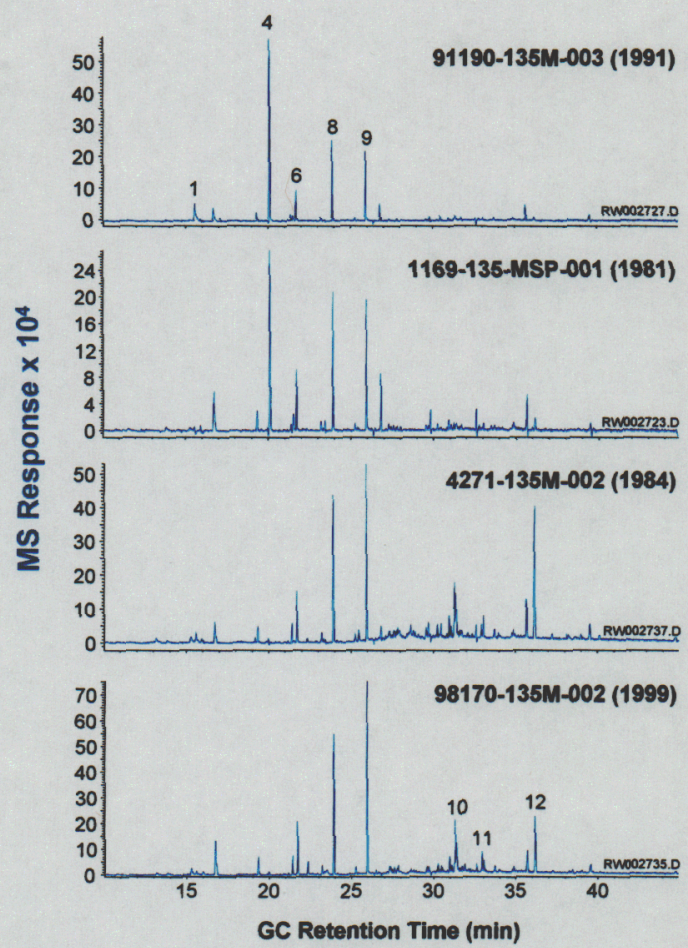

Figure 1. Comparison of mass chromatogram signatures for different lots of ultrafine TATB. Spectra have been blank subtracted. The most significant compounds include peaks (1) toluene, (4) 3-ethoxy-2-methyl-1-propene, (6) octanol, (8) nonanol, (11) an aromatic phenol, (12) an aromatic hydrocarbon, and (13) an aromatic hydrocarbon.

Toluene is one of the synthesis aids that is trapped as the TATB crystals are formed during the TCTNB amination step. Our current understanding is that toluene is intercalated or trapped in pockets by the TATB microstructure. Toluene may be freed from this structure upon mechanical damage to the crystalline structure. Although TATB undergoes a significant degree of mechanical damage during the micronization process, toluene diffusion is slowed by its apparent affinity to TATB. This relatively high affinity is attributed to the conjugated $p i$ structure and polar functional groups of TATB. Thus, we would expect older material, if exposed to similar temperature environments, to have less total toluene. In fact, we see this correlation in the results shown in Table I. Upon comparison of the different lots we see that the oldest lot (i.e., 1161-135MPS-001), which was formulated in 1981, yielded the lowest toluene level of $1.1 \mu \mathrm{g} / \mathrm{g}$. Lot 98170-135M001 , had less toluene than lot $4271-135 \mathrm{M}-002$ possibly because of losses that may have occurred during its reprocessing (see Appendix). It is important to note that it is unlikely that toluene, as well as other formulation ingredients, are not likely distributed homogeneously throughout the TATB. In our analysis of TATB lot 13-03-85-0307-538 (LLNL \# C084), which is a wet-aminated TATB (not an emulsion-aminated TATB), we demonstrated a $25 \%$ relative standard deviation (RSD) (i.e., standard deviation $/$ mean) in toluene response, as shown in Fig. 2. It is important to note that the sample preparation for these samples was different than that described above. In this case $50 \mathrm{mg}$ of TATB with $2 \mathrm{ml}$ of water was seal in a standard 6-ml headspace vial with a Teflon barrier butyl rubber septum. Following ultrasonication sampling was performed at $22^{\circ} \mathrm{C}$ with a100$\mu \mathrm{m}$ PDMS coated fiber that was exposed for $20 \mathrm{~min}$. We believe that this variation is the result of sample inhomogeneity because experimental precision for toluene headspace analysis is approximately $6 \%$ as demonstrated in Fig. 3. A shorter exposure time of 10 
min was used in sampling the toluene standard because equilibration occurs within $1 \mathrm{~min}$. Given that the difference seen between the three original lots is greater than $25 \%$, we believe the toluene response is indicative of an aging process (e.g., heat, time, mechanical damage) experienced by the different lots.
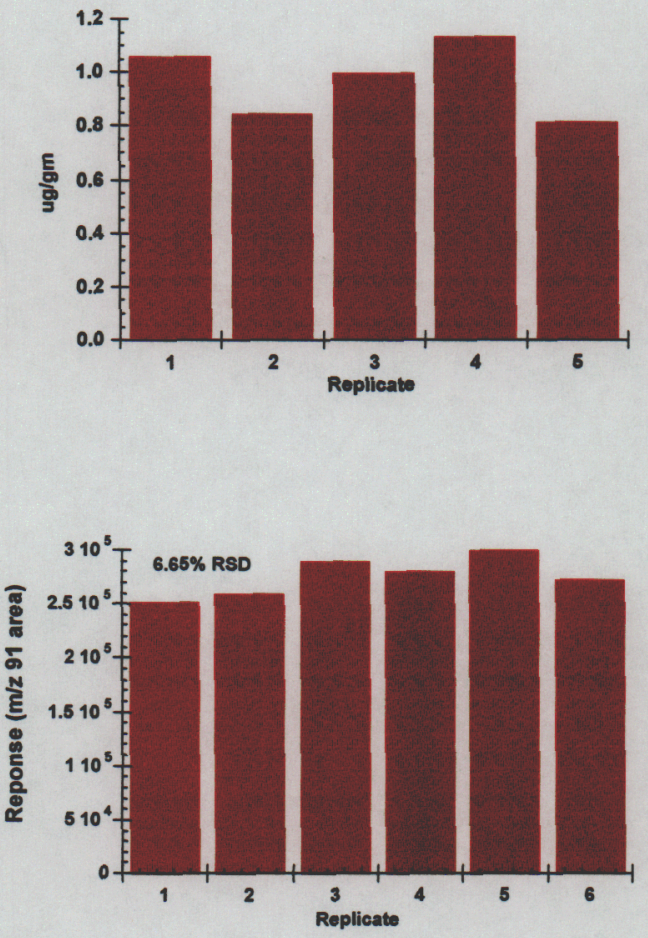

Figure 2. Variation in toluene outgas response results from its inhomogeneous distribution throughout TATB. Lot 1303-85-0307-538 TATB yields a 25\% RSD. Samples were taken with a100- $\mu$ m PDMS coated fiber exposed for $20 \mathrm{~min}$ collection at $22^{\circ} \mathrm{C}$.

Figure 3. Precision of headspace collection and analysis of a 1.72-ppm toluene standard by SPME/GC/MS using a 100- $\mu \mathrm{m}$ PDMS coated fiber and 10 min collection at $22^{\circ} \mathrm{C}$.

The other major synthesis aid in ultrafine TATB is a water/toluene emulsifier, Atlox 5050. This product consists of different polyoxyethylene oligomers combined with an alkyl benzene sulfonate detergent (refer to memo by George Overturf in Appendix). Atlox 5050 is an agricultural emulsifier, and we believed that the alkyl group, $\mathrm{R}$, is likely an unbranched alkane because it is biodegradable. Originally, we thought that the aldehyde products associated with TATB might be synthesis or decomposition byproducts of the alkyl benzene sulfonate. However, upon analysis of archived Atlox 5050 , we did not detect any aldehydes and, thus, concluded that these species might be process or environmental contaminants. In addition, because the samples were outgassed in water, we would not expect to see most of the products and byproducts associated with this emulsifier because of their polar character.

Another unique process contaminant seen at significant levels is 3-ethoxy-2-methyl-1propene. As shown in Table I this compound is highest in the oldest lot (1169-135MPS-001) and newest lot (91190-135M-003). The source of this compound is unknown, but is likely an environmentally introduced contaminant. We do not believe this compound is associated with the polysaccharides. Subsequent analysis of different polysaccharide lots (Stein-Hall, MRL-22A, and Celenese, C-13) did not reveal any compounds traceable back to the ultrafine TATB. This is an expected result because, like the emulsifier, the products associated with the polysaccharides are likely polar watersoluble compounds. 


\section{CONCLUSIONS}

In this work we targeted the analysis of relatively nonpolar compounds trapped as synthesis and formulation aids, process contaminants and degradation products in ultrafine TATB. For collecting these chemicals from TATB, we used a new approach of ultrasonic-assisted outgas sample preparation. This is a trace-level analysis approach that when combined with SPME collection permits analysis of volatile and semivolatiles in the low and sub $\mu \mathrm{g} / \mathrm{g}$ levels from solids.

From these analyses we identified a number of compounds as synthesis aids and process or environmental contaminants in the low $\mu \mathrm{g} / \mathrm{g}$ level. Included among these was toluene, a synthesis aid, that was trapped in the TATB structure during synthesis. We believe relative toluene levels are indicative of differences in synthesis, formulation, and aging environments (e.g., heat, time, mechanical damage). Other formulation ingredients that included a water/toluene emulsifier and a polysaccharide do not appear to contribute to this signature in terms of associated byproducts or decomposition products. At this time we have not identified any compounds that result from decomposition of any of the formulation ingredients. However, we do note the presence of compounds that are attributed to process or environmental contamination. 


\section{Appendix}




\section{Lot 98170-135M-001 Formulation}

300 gm of 1987 lot $4271-135 \mathrm{M}-002$ was combined with $900 \mathrm{gm}$ water. After mixing this combination for approximately $2 \mathrm{hr}$, it was filtered with a Büchner funnel and washed four times with $300 \mathrm{gm}$ water at $40^{\circ} \mathrm{C}$. The resulting cake was then freeze dried for two days. 
TO: Hy Golopol, LLNL

FAX NO.: $\quad 925-423-4897$

FROM: $\quad$ Tom Stallings/Gordon Osborn

PHONE: $\quad 806-477-3593 / 806-477-3592$

Tim Quinlin said you needed a description of the processes used to make the 3 lots of WR Ultrafine TATB.

First WR TATB Lot (Lot No. 1169-135MPS-001):

The TATB for this lot was synthesized by the emulsion-amination method, in which an emulsifier was added to the toluene to cause the water to stay in an emulsion during the amination process. When we micronized the TATB, we used methanol as a defoaming agent during the micronizing process. The total processing time was approximately 12 minutes per pound due to the use of peristaltic pumps to pump the water/methanol/TATB slurry through the micronizer. We had some difficulty in pumping the slurry through the TATB with the peristaltic pumps due to entrained air in the slurry. The micronized TATB was filtered using 5 micron filter cloth and washed with fresh water to remove the methanol. The polysaccharide (which was the old $M R L-22 A$, made by Stein-Hall, Incorporated) was dissolved in water and filtered before adding to the TATB. The polysaccharide was added to the TATB at $0.2 \%$ of the TATB weight. The TATB was then air-dried in filter carts. This gave material which had a Pantex E-Det test breakout distance between $6.5-7 \mathrm{~mm}$ at $-54^{\circ} \mathrm{C}$.

Between the first and second lots of WR TATB, we did a lot of testing and experimenting and found that we were spinning our wheels for much of the last 6 minutes per pound micronization. E-Det testing of batches made at 12 minutes per pound showed no great improvement in divergence over batches made at 6 minutes per pound. We also changed the pump to a LAPP PULSA feeder (diaphragm-type) pump which allowed better control of the flow rate. We also found that adding the polysaccharide before micronizing seemed to help control foaming better than the methanol did. It also eliminated the washing steps to get rid of the methanol before freeze drying.

During this time, Stein-Hall, Incorporated, sold their guar gum (polysaccharide) processes to Celanese Water-Soluble Products. 
Second WR TATB Lot (Lot No. 4271-135M-002):

This lot was also made from emulsion-aminated TATB. Before micronizing, we added $0.2 \%$ wt. \% polysaccharide (which was now the Celanese Water Soluble Polymer's $C-13$ polysaccharide, supposedly the same as the MRL-22A) to the TATB/water slurry and mixed it for about 30 minutes. The polysaccharide was not dissolved in water and filtered before adding to the TATB/water slurry. We micronized the TATB for only 6 minutes per pound before centrifuging to remove excess water and freeze drying. We used a new VirTis freeze dryer to freeze dry this lot. This gave material which had an average E-Det breakout distance of approximately $6.5 \mathrm{~mm}$ at $-54^{\circ} \mathrm{C}$.

Between the $2^{\text {nd }}$ and $3^{\text {rd }}$ lots, we did some more experiments and found that using what we called the "rapid-amination" process, we got a TATB crystal that had nearly the same EDet sensitivity with no micronizing that the emulsion-amination process TATB did after 6 minutes per pound micronization. The rapid-amination process involves dissolving TCTNB in toluene with water, but no emulsifier, and then dumping ammonia into the reactor with high speed agitation, until the pressure drops, indicating the completion of the reaction. The TATB made using this process gave E-Det test divergences between 6.5 and $7 \mathrm{~mm}$ with no additional processing. We found that this TATB gave excellent corner turning using the E-Det test (approximately $5 \mathrm{~mm}$ breakout distance) after 2 minutes per pound verses the 6.5 to $7 \mathrm{~mm}$ breakout distance with the emulsion-aminated TATB after 6 minutes per pound.

Third WR TATB Lot (Lot No. 91190-135M-003):

Therefore for the $3^{\text {rd }}$ lot, we blended approximately $800 \mathrm{lb}$. of rapid-aminated TATB in our 300-gallon kettle and stirred 0.2 wt \% polysaccharide (C-13) into it before micronizing. The polysaccharide was not dissolved in water and filtered before adding to the TATB/water slurry. We pumped the TATB/water/polysaccharide slurry through the micronizer for 2 minutes per pound using our LAPP PULSA feeder pumps. The material was then centrifuged to remove excess water and freeze dried in our new freezer dryer. This gave material which had an average E-Det breakout distance of approximately 5.5 $\mathrm{mm}$ at $-54^{\circ} \mathrm{C}$. 


\section{Weapons Materials Compatibility \& Aging}

Mail Station L-282

Ext: 2-7280

Date: $8 / 31 / 00$

To: Zoher Chiba, L-125

From: George E. Overturf III, L-282

Subject: Change in surfactant used for synthesis of TATB used to make UFTATB

It is a constant problem to replace vendors who stop providing a material specified for a WR process. Such was the case with the surfactant used in the wet amination process needed to create the TATB feedstock used in the UFTATB process for the ongoing W87 SLEP. This memo points out the chemical differences between the surfactant used in the past, Atlox 5050, and what was used for the latest batch of UFTATB, Termul 5030.

The wet amination process reacts ammonia with trichlortrinitrobenzene (TCTNB) to yield TATB. This is accomplished by bubbling ammonia gas through an aqueous/toluene emulsion, which is stabilized by a nonionic surfactant, Atlox 5050. The ammonia displaces the chlorine substituents from the trinitrobenzene and the fully aminated product precipitates out of solution.

Luther Belcher of Mason \& Hanger at Pantex was responsible for finding the replacement surfactant used to synthesize the most current batch of UFTATB. His telephone log narrative is attached as Appendix A. In short, when Atlas Chemicals was purchased, the patents for its agricultural products ended up with a company called Uniqema. Unfortunately, Uniqema has not chosen to market Atlox 5050 and has recommended a replacement, Atlox 5030, which they claimed, differed only in that it was based on propylene oxides rather than ethylene oxides. In a simple test performed at Pantex, the Atlox 5030 was observed to stabilize a toluene and water emulsion over the length of a weekend.

The next obstacle was to find the product, which was ultimately found and shipped from Australia. Uniqema had licensed a company called Huntsman Chemical to make the product under the name Termul 5030.

LLNL obtained samples of the original Atlox 5050 and the new Termul 5030. The IR spectrum of the two surfactants shows they are chemically different (figurel). A search of the IR libraries shows that the new Termul 5030 is very similar to Durfax 60 (aka TWEEN 40, figure 2).

TWEEN 40 is a palmitic ester of sorbitol and its anhydrides copolymerized with ethylene oxide to form a nonionic surfactant. Tweens are soluble or well dispersible in water (HLB 15.6) ${ }^{1}$ with the hydrophilic character supplied by the ethylene oxide and the lipophilic portion is found in the long chain fatty acids used. Figure 3 gives a general structure for TWEEN 40.

\footnotetext{
' McCutcheon s Emulsifiers \& Detergents, 1985 North American Edition, University of California
}

\section{Lawrence Livermore National Laboratory}




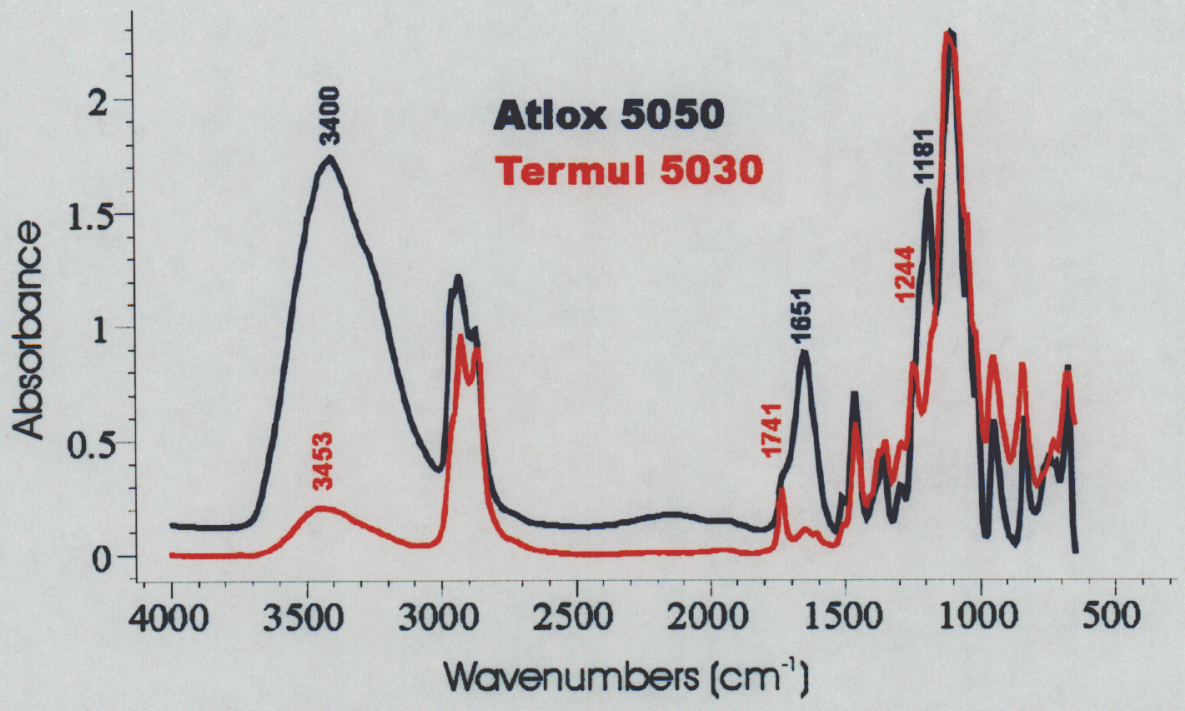

Figure 1. IR spectras of Atlox 5050 and Termul 5030. Both samples measured on a SpectraTech Horizontal ATR (ZnSe $60^{\circ}$ ) and then corrected for ATR and baseline. Key differing peaks are labeled.

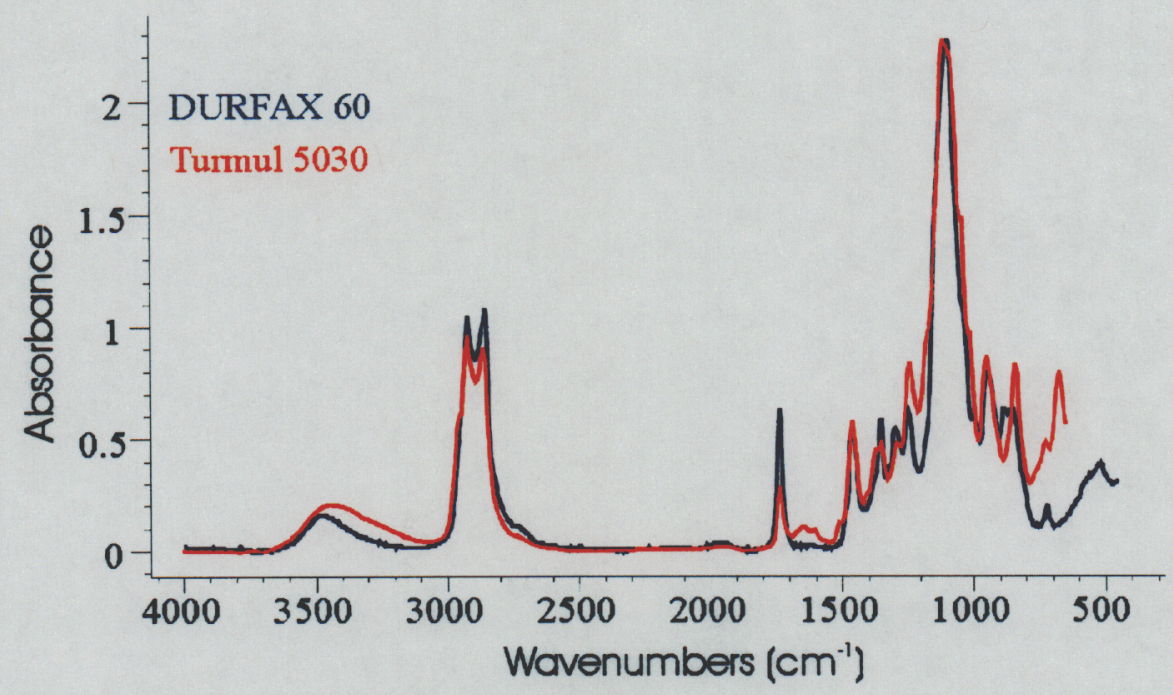

Figure 2. Library match of Termul 5030 with Durfax 60.<smiles>[R]CCCOC(OCC)C1(CO)OCC([N+]([O-])OCCO)C1OCCO</smiles>

Figure 3. General structure of TEEN 40 where the sum of $w, x, y, z=10$ and $R$ is $\left(C_{17} H_{33}\right) C O O$. 
No direct match was made for the Atlox 5050 spectrum with the closest spectrum being for a product named GAFSTAT S. The STN Registry database lists this as a antifoaming agent which contains ammonium lauryl sulfate, Alipal CO 436 (Poly(oxyethylene) nonylphenyl ether ammonium sulfate), stabilizers Aerosol 18 (Succinamic acid, N-octadecyl-2-sulfo-, disodium salt), Duowet EHS (unspecified molecular formula), and dispersant Antaron PC 37 (unspecified molecular formula).

Luther Belcher received a communication from Frank Hartman of Uniqema in which a similar surfactant from their line of products, Atlox 5030 , is described as a blend of alkyl aryl sulfonate and alkyl aryl polyoxyethylene polyoxypropylene and polyoxyethylene sorbitan ester.

From its IR and the preceding information, we can conclude that Atlox 5050 is most probably a mixture. The band at $1181 \mathrm{~cm}^{-1}$ would be consistent with that for an alkyl aryl sulfonate $e^{2}$ and the band at $1651 \mathrm{~cm}^{-1}$ may be due to $\mathrm{C}=\mathrm{C}$ aromatic stretch.

Since the surfactant apparently performs its function in the synthesis, the only lingering questions are in regard to long-term compatibility. David Chambers ${ }^{3}$ has shown that TATB is a sink for organic molecules ( e.g. the toluene used in synthesis) and his SPME analyses of volatiles in UFTATB have yielded the species listed in Table I.

Given the fact that UFTATB batch 91190 did not use a surfactant, it is difficult to find a species for which the 1169 and 4271 batches are equal and significantly higher than the former. This suggests that each of these species is from something other than the surfactant, i.e. the polysaccharide.

Table I Outgas signature list for ultrafine TATB (from Chambers ${ }^{3}$ )

\begin{tabular}{|l|r|r|r|c|}
\hline Compound & 1169-135-MPS01 & 4271-135M-02 & 91190-135M-003 & MW (amu) \\
\hline toluene & 254,688 & 906,008 & $1,601,847$ & 92 \\
\hline hexanal & 392,518 & 445,141 & 215,403 & 100 \\
\hline heptanal & 107,353 & 179,201 & 98,207 & 114 \\
\hline 3-ethoxy-2-methyl-1-propene & $2,108,865$ & Not detected & $4,589,364$ & 100 \\
\hline benzaldehyde & 154,311 & 12,768 & 109,401 & 106 \\
\hline octanal & 123,630 & 195,922 & 132,355 & 128 \\
\hline octanol & 21,527 & 43,306 & 14,913 & 130 \\
\hline nonanal & 154,140 & 359,016 & 172,782 & 142 \\
\hline decanal & 444,002 & 112,662 & $1,647,012$ & 156 \\
\hline DBQ & $\mathrm{ND}$ & 480,624 & 16,597 & 220 \\
\hline aromatic phenol & 13,597 & 262,974 & 25,740 & 180 \\
\hline aromatic hydrocarbon & 2,835 & 75,326 & 146,725 & unk \\
\hline aromatic hydrocarbon & 144,944 & $3,336,674$ & 75,128 & 236 \\
\hline
\end{tabular}

In conclusion, there are no apparent issues with the use of the new surfactant. SPME measurements should be to be performed on the new UFTATB batch for comparison to the preceding three batches. This memo documents that there has been a change of surfactants and that our prediction is that the impact should be negligible.

\footnotetext{
${ }^{2}$ Socrates, G., In Infrared Characteristic Group Frequencies; Wiley \& Sons: New York, 1994; p 169.

${ }^{3}$ Chambers, D. Outgas Analysis of Trapped Compounds in Ultrafine TATB; Technical Report; Lawrence Livermore National Laboratory: Livermore, CA, 2000.
} 
TABLE A

The search (and continuing saga) for ATLOX 5030:

On 10-7-99, search initiated with this initial information: State Chemicals purchased Atlas Chemicals State Chemicals was purchased by ICI and split two ways:

- Agricultural chemicals went to Uniqema

- Industrial chemicals went to Stepan

10-12-99, Samples of ATLOX 5030, 4912, and 4914 (all ATLOX) were ordered from Uniqema

10-29-99, Samples of MAKON 4, 8, 10, and 12 (all MAKON) were ordered from Stepan

Reason: ATLOX 5030 is the closest product to ATLOX 5050 (used originally) which is no longer produced. ATLOX 5030 is propylene-oxide-based rather than ethylene-oxide-based. Thermal stability was a question. Uniqema recommended ATLOX 4912 \& 4914.

MAKONs were recommended by Technical representatives for Stepan \& ordered

11-4-99 ATLOX reception at Plant.

11-9-99 MAKONs reception at Plant.

11-11-99, samples delivered to 11-17.

All samples were mixed with Toluene \& water to determine emulsifying ability and left to settle to determine static emulsifying ability.

All seemed to emulsify under agitation; but each had varying emulsifying ability under static conditions. Most samples maintained a least a partial emulsion at the liquid/oil interface.

ATLOX 5030 maintained a complete emulsion over the weekend, no split was observed.

ATLOX 5030 was chosen for small-scale TATB-emulsion-amination runs.

Runs conducted and samples distributed for $\mathrm{Cl}$ content determination and for SEM pictographs.

On $12 / 15 / 99, \mathrm{Cl}$ content was way below expectations and crystal formation was satisfactory demonstrating more than adequate thermal stability for proposed operating conditions.

On 12-20-99 through 12-23-99, Uniqema was contacted about ordering ATLOX 5030. Will provide price.

Plant shutdown over Christmas \& New Year s.

On 1-4-00, Uniqema representatives called to say that ATLOX 5030 was not available domestically, however, it was in the UK database. Steps required: 1) setup as new customer, 2) add 5030 to North American range, 3) supply through a distributor, 4) Significant amounts? Mr. Greg Lindner, Technical Manager for Crop Protection additives was contacted. Uniqema was continuing to provide a price determination.

Simultaneously on $1 / 4 / 00$, Lydia King was contacted about ordering Internationally. She suggested two folks: 1) Darrel Hanson, Fischer-Scientific, and 2) Michele Knight, Genesis, to work on ordering the material. Both were contacted. Darrel Hansen was only person that called back and continued contact and work.

1/5/00, Darrel Hanson was provided the name and number of Igor Aksman who should be able to provide ATLOX 5030. Left for Darrel to provide cost estimate. It turned out; Darrel had a hard time contacting Igor, so I initiated contact again.

1/12/00 per Igor, ATLOX 5030 available in Europe and not sold in the USA. Igor gave the name of two local sales Uniqema sale reps: 1) Greg Grant, Ag products, Plano TX, and 2) John Telford, Industrial products, Woodland TX. Both contacted, ATLOX is AG, so Greg Grant was tasked to deliver quote. Three options discussed: 1) sell ATLOX 5030,2) sell three components and let us mix, and 3) deliver a 120 pound sample to us. 
$1 / 19 / 00$, Greg Grant is meeting with Wilmington, DE folks (Corporate) about the ATLOX 5030 sale. Will call after meeting. It s a Business Mana gement decision. Didn $t$.

$1 / 20 / 00$, began search again through ICI website. Multiple contacts made with listed explosives Tech reps. Obtained Belgium number for Uniqema (can only call early mornings, time difference).

$1 / 21 / 00$, Greg called. Meeting at Corporate unsuccessful. Snowstorm first day, moving second day. Will return 1-24-00 and call to let me know results.

1/24/00, Called Belgium. ATLOX 5030 is NOT in European database. But, subsidiary, Orica, in Melbourne, Australia still used it. Website search discovers MSDS for ATLOX 5030. Company contacted. Domestic distributors contacted. NA corporate Hqtrs in Englewood CO. They are working on price quote. Called Orica distributor, Titan Energy in Santa Fe, who said that Lubrizol made most of Orica s surfactants and even blended formulations. Most blending performed on Oklahoma.

Lubrizol contacted about ATLOX 5030. Jeff will call back.

Surfactants sold to Huntsman Corp., Melbourne. They transferred me to Athanasia. ATLOX tradename was not sold; Termul 5030 is the same material. She would provide by fax: 1) Domestic distributor, if available, 2) msds, and 3) price for 50-100 gallons.

1/25/00, no fax. Assumption was that domestic distributor available. Websearch discovered Huntsman, Corp. in UT. Marc Chouinard contacted. He will answer questions: 1) off-the-shelf? 2) price for 50-100 gallons, 3) timeline for delivery, 4) provide a sample.

Jeff, Lubrizol, says that they cannot supply the material.

MSDS for TERMUL 5030 will be faxed for PX-761 submittal before sample is shipped. Sample will ensure that material is what we want before special blend is formulated or any other special considerations are exercised.

1-26-00, Greg called and gave me Byron McGee s, Texas, Houston?, number. $\mathrm{He}$, or his product manager, would make the decision to sell us the material.

NOTE: 1 . one constituent made in Wilmington,

2. 2 constituents made in Europe

3. one of the constituents made in Europe is delivered to USA due to limited, but growing customer use.

4. for $120 \# \mathrm{~s}$, setting up a purchasing system may not be worthwhile. Greg s recommendation

1-26-00, Byron calls. (281) 537-9799, cellular (713) 501-7255. He wants to get whatever we want $/$ need. He will provide price for answer to off-the-shelf?, 50-100 gallons pride, timeline for delivery of the blend or constituents, and price/timeline/constituents for initial 120\# $\mathrm{s}$. The first may come as samples after I explained timelines. I explained that at this time, purchasing system injection was goal. First run scheduled for April 1, 00.

1-28-00, Marc, Huntsman Corp., called and said that the material is routinely made in Australia. He emailed pricing information with delivery costs and timelines for delivery. Butanol is used in Australia and that entails freight as a Class III flammable with increased costs; however, air freight may be what we want due to expediency. Australia will be contacted this Sunday to Fax an MSDS and send a 1-2 oz. sample. Not convinced that TERMUL 5030 is exactly ATLOX 5030. MSDS should be here Monday or Tuesday and the sample should be here 7-10 days.

1-31-00, I called Marc who said that the sample was ordered Friday. He 11 follow up to ensure it $\mathbf{s}$ delivered. Should take 7-10 days. 
2-3-00, I called Byron at Uniqema. No luck, but he would continue the search for the product.

2-4-00, I e-mailed Marc and Paul ( $\mathrm{Au})$ about tracking number and status of sample.

2-8-00, Received fax with commercial invoice and Airwaybill. It looks like the material will be delivered to Dallas. No information about how it will get to us. I e-mailed Marc and Paul again to ask how it will get to us. I e-mailed them again to request that a sample be sent on FedEx who delivers to our door. Called transportation, Pat. No new information forthcoming.

2-8-00, I called ALM to see about shipment because I have heard nothing from everyone.

2-8-00, Two Plant operators try and can $t$ get through to Australia.

2-9-00, No communication from Huntsman. I called Marc and explained the situation. He would research and figure it out. I called Pat again, no new ideas. FedEx was called for ideas and pricing. FedEx cannot deliver OUT-OF Australia, only IN-TO. They explained the situation to me, someone would have to receive the material at Dallas and assume shipper s responsibility to get it to us. United Airlines said the same thing, but couldn $t$ recommend one or who to call. FedEx recommended Quintas Airlines. When called, Quintas said they would deliver from Melbourne to Amarillo for $\$ 100.00$.

I asked Tim about $\$ 100.00$ and we went to Lou. Lou called purchasing who said that a req wasn $t$ needed for a free sample and Transportation, Beyers, could approve the freight. Lou will talk to Beyers. Lou wanted information: sample name \& Company name. I e-mailed her sample name, company name, address, telephone number, and contacts with e-mail and telephone numbers. They will take care of getting the sample delivery process. If they, Lou and Beyers, handle it, transportatio will pick it up at the airport and delive it to Pantex.

End of search. Potential product found, submitted PX-761 (with MSDS) to IH, tried to get a sample and failed, contacts delivered to Lou (phone numbers and e-mails), and turned it over to purchasing. I also provided the information that Quantas Airlines will deliver to Amarillo from Melbourne for $\sim \$ 100.00$.

I e-mailed Huntsman and told them I would let them know our next step.

n:Iwordlatlox 5030. doc 